\title{
Lewis acidic (choline chloride.3ZnCl 2 ) ionic liquid: A green and recyclable catalyst for the one-pot synthesis of 4-((3-indolyl)(aryl)methyl)-N,N-dimethylanilines under solvent-free conditions
}

\author{
RAHIM HEKMATSHOAR*, FARNOUSH MOUSAVIZADEH \\ and REYHANEH RAHNAMAFAR \\ Department of Chemistry, School of Science, Alzahra University, Vanak, Tehran, Iran \\ e-mail: rhekmatus@yahoo.com
}

MS received 5 February 2013; revised 1 April 2013; accepted 16 April 2013

\begin{abstract}
A green and convenient procedure for the one-pot multicomponent synthesis of 4-((3indolyl)(aryl)methyl)-N,N-dimethylanilines using (choline chloride. $3 \mathrm{ZnCl}_{2}$ ) ionic liquid as catalyst, at $100^{\circ} \mathrm{C}$ and under solvent-free condition is described. Utilizing environmentally benign reagents, elimination of organic solvents, enhanced rates, reusability and moisture stability of the catalyst are the remarkable features observed in the reported reaction system. The catalyst was recycled up to four times with no noticeable drop in activity.
\end{abstract}

Keywords. Choline chloride; zinc chloride; ionic liquid; one-pot; triarylmethane.

\section{Introduction}

In the present era of chemical synthesis, avoidance of toxic solvents and reagents, reduction of waste and creating reusable reaction media are the key interests of synthetic organic chemists world over. ${ }^{1,2}$ In this context, ionic liquids are the versatile alternative, as a result of their green credentials such as undetectable vapour pressure, reusability and high thermal stability. ${ }^{3,4}$ Recently, imidazolium-based ionic liquids have been extensively used as solvents and catalysts in organic synthesis. ${ }^{5-8}$ However for practical utilization, these ionic liquids are high toxic, relatively expensive, highly sensitive to water and have a difficult preparation process. ${ }^{9}$ Choline Chloride. $\mathrm{XnCl}_{2}\left(\mathrm{ChCl} \mathrm{xZnCl} \mathrm{ZnC}_{2}\right)$ ionic liquid acts as a powerful replacement for the more commonly employed imidazolium-based ionic liquids. ${ }^{10}$ Easy preparation methods, low cost, air and moisture stability, green nature and reusability are the benefits which opens up the possibility of its use in large-scale applications such as zinc electroplating ${ }^{11}$ and batteries. ${ }^{12}$ It has also been used as reaction media for Diels-Alder reaction, ${ }^{13}$ Fischer indole synthesis, ${ }^{14} \mathrm{O}$ acetylation of cellulose and monosaccharides ${ }^{15}$ and protection of carbonyl groups. $^{9}$

Motifs bearing triarylmethane and their heterocyclic variants have received enormous attention due to their ubiquitous applications as leuco dyes, ${ }^{16}$ photochromic

*For correspondence agents ${ }^{17,18}$ and are an integral part of many bioactive compounds, prodrugs and pharmaceuticals. ${ }^{19-21}$ Triarylmethanes containing indole nucleus are of much importance as they are widely distributed in nature and used in drug design. ${ }^{22-24}$ The principle synthetic avenue to triarylmethanes comprises a double FriedelCrafts reaction of an aromatic aldehyde with electronrich aromatic compounds, which prevalently gives rise to the formation of symmetrical triarylmethanes. There are also few methods, developed specifically for the synthesis of unsymmetrical triarylmethanes in which a complex and multi-step process is their main drawback. As a consequence, the synthesis of unsymmetrical derivatives is still a challenging and less-explored area. ${ }^{25-29}$

In this study, we present a green protocol for the synthesis of 4-((3-indolyl)(aryl)methyl)-N,N-dimethylanilines as an unsymmetrical triarylmethane in a one-pot multicomponent method using $\left(\mathrm{ChCl} .3 \mathrm{ZnCl}_{2}\right)$ ionic liquid as an efficient and recoverable catalyst under solvent-free conditions (figure 1).

\section{Experimental}

\subsection{Chemicals and apparatus}

All the chemicals were purchased from Merck. Melting points were measured by using the capillary tube method with an electrothermal 9200 apparatus. 


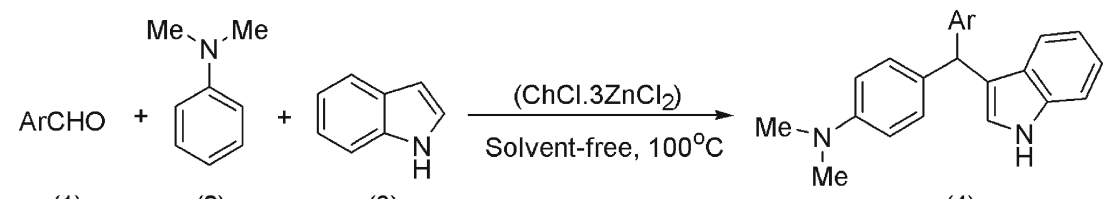

(1)

(2)

(3)

(4)

Figure 1. Choline chloride. $3 \mathrm{ZnCl}_{2}$ catalysed synthesis of 4-((3-indolyl)(aryl)methyl)-N,N-dimethylanilines .

${ }^{1}$ Hydrogen-Nuclear Magnetic Resonance (HNMR) and ${ }^{13}$ Carbon-Nuclear Magnetic Resonance (CNMR) spectra were recorded on a Bruker AQS AVANCE-250 MHz spectrometer, using Tetramethylsilane (TMS) as an internal standard $\left(\mathrm{CDCl}_{3}\right.$ solution). Infrared (IR) spectra were recorded on the Fourier Transform-Infrared (FT-IR) Bruker Tensor 27. Mass spectra were documented on an Agilent Technology (HP) mass spectrometer operating at an ionization potential of $70 \mathrm{eV}$.

\subsection{Preparation of choline chloride. $3 \mathrm{ZnCl}_{2}$ ionic liquid}

Choline chloride $(20 \mathrm{mmol})$ was mixed with zinc chloride $(60 \mathrm{mmol})$ and heated to $150^{\circ} \mathrm{C}$ with stirring until a clear colourless liquid was obtained. ${ }^{30}$

\subsection{General procedure for the preparation of 4-((3-indolyl)(aryl)methyl)- $N, N$-dimethylanilines}

A mixture of aldehyde $(1 \mathrm{mmol})$, indole $(1 \mathrm{mmol}$, $0.117 \mathrm{~g}), \mathrm{N}, \mathrm{N}$-dimethylaniline $(1 \mathrm{mmol}, 0.121 \mathrm{~g})$ and $0.165 \mathrm{~g}(30 \mathrm{~mol} \%)$ of $\left(\mathrm{ChCl} 3 \mathrm{ZnCl}_{2}\right)$ ionic liquid was heated to $100^{\circ} \mathrm{C}$ in an oil bath for an appropriate time (table 1). After completion of the reaction, as indicated by Thin Layer Chromatography (TLC), the catalyst was removed by extraction with water and ethyl acetate. Subsequently, the solvent of the organic phase was evaporated and $7 \mathrm{ml}$ of ethanol was added to the residue. After precipitation of the target compound, it was filtered, washed with ethanol and dried. All of the products (except $\mathbf{4 g}$ and $\mathbf{4 h}$ ) were known and their physical data were compared with those of authentic samples in the literature ${ }^{31}$ and found to be identical. Also physical and spectral data for new derivatives (4g and $\mathbf{4 h}$ ) are given.

\subsection{Physical and spectral data for new derivatives}

2.4a 4-((3-Indolyl)(4-fluorophenyl)methyl)- $N, N$ dimethylaniline $(\mathbf{4 g})$ : $\mathrm{Mp} 146-147^{\circ} \mathrm{C}$; white compound; IR(KBr) 3414, 3176, 3037, 1609, 1506, 1331, $1221 \mathrm{~cm}^{-1}$; ${ }^{1} \mathrm{H}$ NMR $(250 \mathrm{MHz}, \mathrm{CDCl} 3) 7.94(\mathrm{~s}, 1 \mathrm{H})$, $7.35(\mathrm{~d}, J=8.00 \mathrm{~Hz}, 2 \mathrm{H}), 7.16(\mathrm{~m}, 8 \mathrm{H}), 6.67(\mathrm{~d}, J=$ $8.50 \mathrm{~Hz}, 2 \mathrm{H}), 6.57(\mathrm{~s}, 1 \mathrm{H}), 5.56(\mathrm{~s}, 1 \mathrm{H}), 2.92(\mathrm{~s}, 6 \mathrm{H})$; ${ }^{13} \mathrm{C}$ NMR(63 MHz, CDCl3) 163.2, 159.4, 149.1, 140.4, $136.7,131.9,130.3,130.2,129.5,127.0,123.9,122.1$, 120.6, 120.0, 119.3, 115.0, 114.7, 112.6, 111.0, 47.1, 40.7; MS $(\mathrm{m} / \mathrm{z}) 344\left(\mathrm{M}^{+}\right), 249,222,124$.

2.4b 4-((3-Indolyl)(3-bromophenyl)methyl)- $N, N$ dimethylaniline (4h): $\mathrm{Mp} 169-171^{\circ} \mathrm{C}$; White compound; IR(KBr): 3397, 3241, 3111, 3054, 1611, 1516, $1475 \mathrm{~cm}^{-1} ;{ }^{1} \mathrm{H}$ NMR $(250 \mathrm{MHz}, \mathrm{CDCl} 3) 7.95$ (s, 1H), $7.35(\mathrm{~m}, 4 \mathrm{H}), 7.09(\mathrm{~m}, 6 \mathrm{H}), 6.67(\mathrm{~d}, J=8.75 \mathrm{~Hz}, 2 \mathrm{H})$, $6.59(\mathrm{~s}, 1 \mathrm{H}), 5.55(\mathrm{~s}, 1 \mathrm{H}), 2.93(\mathrm{~s}, 6 \mathrm{H}) ;{ }^{13} \mathrm{C}$ NMR $(63$ $\mathrm{MHz}, \mathrm{CDCl} 3)$ 149.2, 147.2, 136.7, 131.9, 131.3, 129.8, $129.5,129.2,127.6,126.9,124.0,122.4,122.1,120.7$, $119.9,119.4,112.7,111.1,47.6,40.7$; MS $(\mathrm{m} / \mathrm{z}) 404$ $\left(\mathrm{M}^{+}\right), 340,249,233,204,124$.

Table 1. Synthesis of 4-((3-indolyl)(aryl)methyl)-N,N-dimethylanilines using $\left(\mathrm{ChCl}_{3} 3 \mathrm{ZnCl}_{2}\right)$ ionic liquid as catalyst ${ }^{\mathrm{a}}$.

\begin{tabular}{llllllll}
\hline & & & & & \multicolumn{2}{c}{$\mathrm{mp}\left({ }^{\circ} \mathrm{C}\right)$} \\
\cline { 6 - 8 } Entry & \multicolumn{1}{c}{ Aldehyde } & Product & Time $(\min )$ & Yield $(\%)$ & Found & Reported 31 \\
\hline 1 & Benzaldehyde & $\mathbf{4 a}$ & 15 & 77 & $157-159$ & $161-162$ \\
2 & 4-Methylbenzaldehyde & $\mathbf{4 b}$ & 35 & 75 & $169-170$ & $164-165$ \\
3 & 4-Methoxybenzaldehyde & $\mathbf{4 c}$ & 90 & 43 & $168-169$ & $162-164$ \\
4 & 3-Methoxybenzaldehyde & $\mathbf{4 d}$ & 75 & 73 & $149-150$ & $151-153$ \\
5 & 2-Naphthaldehyde & $\mathbf{4 e}$ & 20 & 57 & $156-157$ & $151-152$ \\
6 & 4-Chlorobenzaldehyde & $\mathbf{4 f}$ & 45 & 69 & $134-135$ & $130-132$ \\
7 & 4-Fluorobenzaldehyde & $\mathbf{4 g}$ & 15 & 64 & $146-147$ & - \\
8 & 3-Bromobenzaldehyde & $\mathbf{4 h}$ & 35 & 81 & $169-171$ & - \\
\end{tabular}

${ }^{a}$ Reaction conditions: aldehyde $(1 \mathrm{mmol})$, indole $(1 \mathrm{mmol})$, N,N-dimethylaniline $(1 \mathrm{mmol}),\left(\mathrm{ChCl} .3 \mathrm{ZnCl}_{2}\right)(30 \mathrm{~mol} \%)$, solvent-free, oil bath heated to $100^{\circ} \mathrm{C}$ 
Table 2. Effect of different mol ratios of choline chloride to $\mathrm{ZnCl}_{2}$

\begin{tabular}{llcc}
\hline Entry & \multicolumn{1}{c}{ Catalyst } & Time (min) & Yield (\%) \\
\hline 1 & Choline chloride & 180 & Nil \\
2 & Choline chloride. $\mathrm{ZnCl}_{2}$ & 15 & 62 \\
3 & Choline chloride. $2 \mathrm{ZnCl}_{2}$ & 15 & 66 \\
4 & ${\text { Choline chloride. } 3 \mathrm{ZnCl}_{2}}_{2}$ & 15 & 77 \\
5 & $\mathrm{ZnCl}_{2}$ & 15 & 72 \\
\hline
\end{tabular}

Table 3. Effect of catalyst loading on three-component reaction of aromatic aldehydes, indole and N,N-dimethylaniline.

\begin{tabular}{lccc}
\hline & $\begin{array}{c}\text { Amount of } \\
\text { Entry } \\
\text { catalyst (mol\%) }\end{array}$ & Time (min) & Yield (\%) \\
\hline 1 & 0 & 180 & Nil \\
2 & 5 & 15 & 62 \\
3 & 10 & 15 & 67 \\
4 & 20 & 15 & 68 \\
5 & 30 & 15 & 77 \\
6 & 40 & 15 & 69 \\
7 & 50 & 15 & 54 \\
\hline
\end{tabular}

\section{Results and discussion}

Initially, the reaction between indole, benzaldehyde and $\mathrm{N}, \mathrm{N}$-dimethylaniline was chosen as the model reaction in order to investigate the effect of different mole ratios of choline chloride to $\mathrm{ZnCl}_{2}$ on the yield of the products and reaction time. In this way, the reaction was carried out in an oil bath heated to $100^{\circ} \mathrm{C}$, under solvent-free condition, loading $30 \mathrm{~mol}$ percent of ionic liquids with various mol ratios of choline chloride to $\mathrm{ZnCl}_{2}$. The results are outlined in table 2. As indicated, the best result was obtained when $\left(\mathrm{ChCl} 3 \mathrm{ZnCl}_{2}\right)$ ionic liquid was utilized. It is noteworthy that by using choline chloride alone, no significant product formation was observed, highlighting the fact that the presence of zinc chloride is necessary for this reaction. The lower yields obtained from the reactions catalysed by $\left(\mathrm{ChCl} . \mathrm{ZnCl}_{2}\right)$ and $\left(\mathrm{ChCl} .2 \mathrm{ZnCl}_{2}\right)$ ionic liquids may be attributed to Lower lewis acidity in the two aforementioned catalysts. Abbott et al. ${ }^{30}$ have demonstrated that the actual species present in $\left(\mathrm{ChCl} \mathrm{xZnCl} \mathrm{Zn}_{2}\right)$ ionic liquid are Lewis acidic chlorozincate clusters $\left(\mathrm{ZnCl}_{3}^{-}\right.$, $\mathrm{Zn}_{2} \mathrm{Cl}_{5}^{-}$and $\mathrm{Zn}_{3} \mathrm{Cl}_{7}^{-}$). It is postulated that existence of a chloride ion in these clusters may diminish the Lewis acidity in comparison with free zinc chloride catalyst. Recently, it has been disclosed that these Lewis acidic clusters can sometimes act as Lewis bases which are even able to abstract a proton in the course of the reaction. ${ }^{32}$ However, we tried to overcome this defect by increasing the mol ratio of zinc chloride in ionic liquid. As revealed in table $2,\left(\mathrm{ChCl} .3 \mathrm{ZnCl}_{2}\right)$ outperforms free zinc chloride catalyst under the same reaction conditions.

In order to optimize the amount of catalyst, the model reaction was performed under the same condition and in the presence of different quantities of $\left(\mathrm{ChCl} .3 \mathrm{ZnCl}_{2}\right)$. As shown in table 3, the optimum amount of catalyst

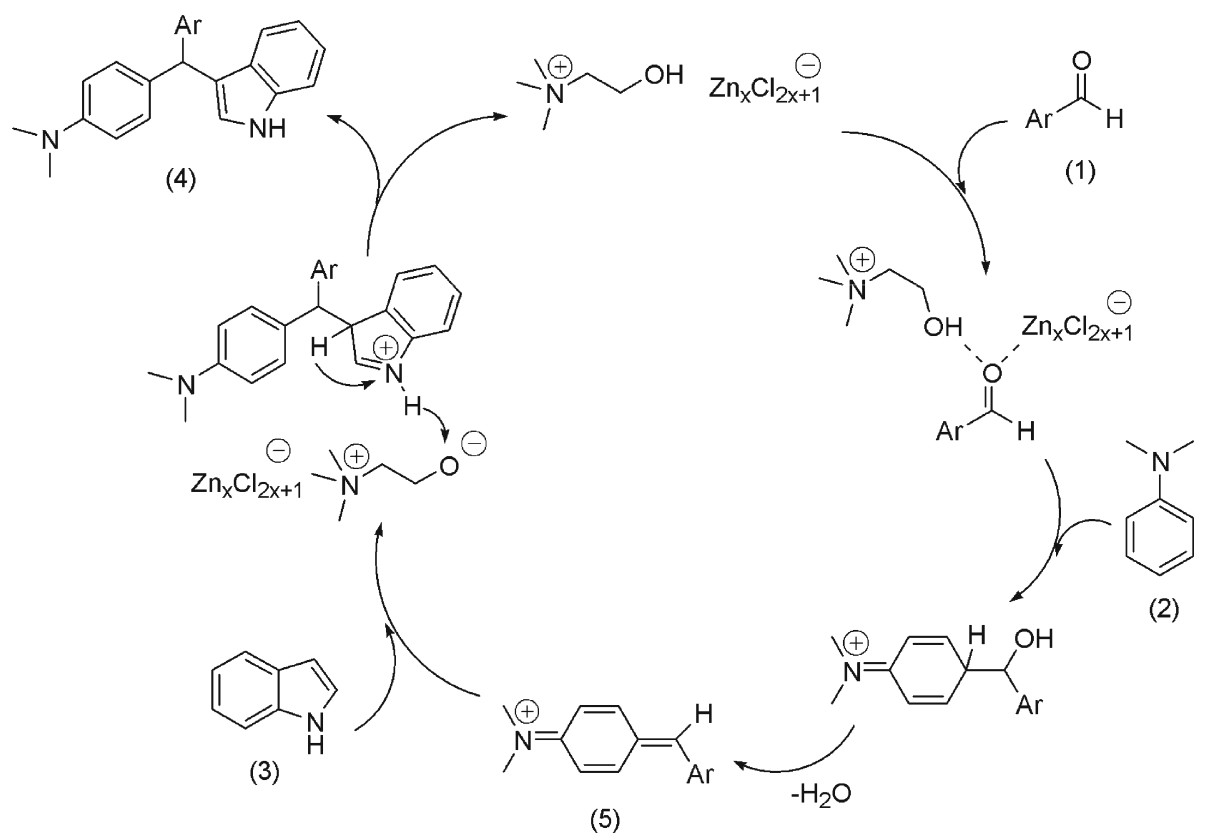

Figure 2. Plausible mechanism for the one-pot synthesis of 4-((3indolyl)(aryl)methyl)-N,N-dimethylanilines using $\left(\mathrm{ChCl} .3 \mathrm{ZnCl}_{2}\right)$ as catalyst. 
Table 4. Evaluation of reusability of catalyst.

\begin{tabular}{lcccc}
\hline Run & 1 & 2 & 3 & 4 \\
\hline Yield (\%) & 77 & 74 & 74 & 71 \\
\hline
\end{tabular}

was $30 \mathrm{~mol}$ percent and further increase in the catalyst loading did not improve the yield of the reaction.

Encouraged by these initial results, the generality of this method was studied applying various aromatic aldehydes. The results are all collected in table 1. Aromatic aldehydes with different substitutions on aromatic ring underwent smooth reaction with indole and $\mathrm{N}, \mathrm{N}$-dimethylaniline, furnishing the respective 4((3-indolyl)(aryl)methyl)-N,N-dimethylanilines in high yields and with considerable shortened reaction time in comparison with the previously reported method for the synthesis of these compounds. ${ }^{31}$

A plausible mechanism of the reaction is presented in figure 2. Activation of carbonyl group by Lewis acidity of chlorozincate clusters as well as formation of a hydrogen bonding with hydroxyl group in choline cation, promotes the reaction of aromatic aldehyde (1) with $\mathrm{N}, \mathrm{N}$-dimethylaniline (2) to generate the intermediate (5), which on addition of indole (3) the corresponding 4-((3-indolyl)(aryl)methyl)-N,N-dimethylaniline (4) is formed. Since Abbott et al. ${ }^{30}$ have demonstrated that the actual species present in $\left(\mathrm{ChCl} . \mathrm{xZnCl}_{2}\right)$ ionic liquid are Lewis acidic chlorozincate clusters $\left(\mathrm{ZnCl}_{3}^{-}, \mathrm{Zn}_{2} \mathrm{Cl}_{5}^{-}\right.$ and $\mathrm{Zn}_{3} \mathrm{Cl}_{7}^{-}$), it cannot be simply expected that just one clearly determined zinc-containing ion is responsible for the Lewis acid activity of the catalyst. Consequently, the $\left[\mathrm{Zn}_{x} \mathrm{Cl}_{2 x+1}\right]^{-}$complex shown in the mechanism, refers to all the zinc clusters present in ionic liquid, which can inherently act as a Lewis acid catalyst.

One of the key advantages of ionic liquids is their ability to function as recoverable catalysts. After each run, the $\left(\mathrm{ChCl}^{3} 3 \mathrm{ZnCl}_{2}\right)$ ionic liquid was simply separated by extraction with water and ethyl acetate. The aqueous phase was washed with ethyl acetate and the water was evaporated. After drying the catalyst at $120^{\circ} \mathrm{C}$ in vacuum for $2 \mathrm{~h}$, it was used in the next run. The recycled catalyst promoted reactions in a similar manner without significant loss of activity (table 4).

\section{Conclusion}

In summary, an environmentally friendly approach for the one-pot multicomponent synthesis of 4-((3indolyl)(aryl)methyl)-N,N-dimethylanilines is established with maximum simplicity and brevity. Taking advantage of substantial catalytic activity of $\left(\mathrm{ChCl}^{3} 3 \mathrm{ZnCl}_{2}\right)$ ionic liquid, reaction times could be significantly reduced. Moreover, this ionic liquid can be readily synthesized and easily recycled without significant loss in catalytic activity. Also, this methodology emphasizes the green chemistry aspects by avoiding toxic catalysts and solvents. Although catalytic activity of free zinc chloride stands out in this reaction, water insensitivity, reusability, ease of handling and storage, non-corrosive and green nature of its choline chloride ionic liquid are the advantages which encouraged us to choose the ionic liquid analogues over the conventional zinc chloride.

\section{Supporting information}

The electronic supporting information can be seen in www.ias.ac.in/chemsci.

\section{Acknowledgement}

The authors are thankful to Alzahra Research Council for partial financial support.

\section{References}

1. Horvath I T and Rabai J 1994 Science 2572

2. Kitazume T, Ishizuka T, Takedu M and Itoh K 1999 Green Chem. 1221

3. Welton T 1999 Chem. Rev. 992071

4. Wasserscheid P and Keim W 2000 Angew. Chem. Int. Ed. 393772

5. Hu S, Zhang Z, Song J, Zhou Y and Han B 2009 Green Chem. 111746

6. Peng J and Deng Y 2001 Tetrahedron Lett. 425917

7. Li C and Zhao Z K 2007 Adv. Synth. Catal. 3491847

8. Itoh T, Nishimura Y, Ouchi $\mathrm{N}$ and Hayase $\mathrm{S} 2003 \mathrm{~J}$. Mol. Catal. B: Enzym. 2641

9. Duan Z, Gu Y and Deng Y 2006 Catal. Commun. 7651

10. Abbott A P, Capper G, Davies D L, Munro H and Rasheed R K 2004 Inorg. Chem. 433447

11. Abbott A P, Capper G, Davies D L, Rasheed R K and Tambyrajah V 2001 Trans. Inst. Met. Finish. 79204

12. Abbott A P, Capper G, Davies D L, Munro H, Rasheed R K and Tambyrajah V 2003 Ionic liquids as green solvents: Progress and prospects, $\mathrm{R} \mathrm{D}$ Rogers and $\mathrm{K} \mathrm{R}$ Seddon (Eds), Washington D C: ACS Symposium Series, American Chemical Society, pp. 439-452

13. Abbott A P, Capper G, Davies D L, Rasheed R K and Tambyrajah V 2002 Green Chem. 424

14. Morales R C, Tambyrajah V, Jenkins P R, Davies D L and Abbott A P 2004 Chem. Commun. 158

15. Abbott A P, Bell T J, Handa S and Stoddart B 2005 Green Chem. 7705

16. Muthyala R 1997 Chemistry and applications of leuco dyes, A R Katrizky and G J Sabongi (Eds), Plenum: New York

17. Duxbury D F 1993 Chem. Rev. 93381

18. Aldag R 1990 Photochroism: molecules and systems, $\mathrm{H}$ Durr and H Bouaslaurent (Eds), Elsevier: London 
19. Oclarit J M, Ohta S, Kamimura K, Yamaoka Y, Shimizu T and Ikegami S 1994 Nat. Prod. Lett. 4309

20. Mibu N, Yokomizo Y, Uyeda M and Sumoto K 2003 Chem. Pharm. Bull. 511325

21. Poupelin J P, Saint-Ruf G, Foussard-Blanpin O, Narcisse G, Uchida-Ernouf G and Lacroix R 1978 Eur. J. Med. Chem. 1367

22. Gribble G W 1996 Comprehensive heterocyclic chemistry, 2nd edn Pergamon Press: New York vol. 2, pp 203-257

23. Snieckus V 1968 The alkaloids, Academic Press: New York, vol. 11, pp 1-33
24. Gul W and Hamann M T 2005 Life Sci. 78442

25. Katritzky A R and Lan X 1994 Dyes Pigments 25303

26. Deb M L and Bhuyan P J 2008 Synthesis 2891

27. Esquivias J, Arrayas R G and Carretero J C 2006 Angew. Chem. 118645

28. Das S K and Shagufta 2005 Tetrahedron Lett. 463097

29. Katrizky A R and Toader D 1997 J. Org. Chem. 624137

30. Abbott A P, Capper G, Davies D L, Munro H, Rasheed R K and Tambyrajah V 2001 Chem. Commun. 2010

31. Liu J, He T and Wang L 2011 Tetrahedron 673420

32. Disale S T, Kale S R, Kahandal S S, Srinivasan T G and Jayaram R V 2012 Tetrahedron Lett. 532277 